Fukushima J. Med. Sci.,

Vol. 48, No. 2, 2002

[Case Reports]

\title{
PREVENTION OF PROGRESSION OF INTERSTITIAL LUNG LESIONS BY EARLY COMBINATION THERAPY WITH CORTICOSTEROIDS AND CYCLOSPORINE/CYCLOPHOSPHAMIDE IN TWO PATIENTS WITH AMYOPATHIC DERMATOMYOSITIS
}

\author{
KOTA SUGISAKI ${ }^{1}$, ISAO TAKEDA ${ }^{1)}$, HARUYO IWADATE ${ }^{1)}$, \\ TAKASHI KANNO'), TOMOE NISHIMAKI ${ }^{2)}$ \\ and REIJI KASUKAWA ${ }^{1)}$ \\ ${ }^{1)}$ Division of Rheumatology, Ohta Nishinouchi Hospital, Koriyama \\ 2) Nishimaki Clinic, Sukagawa
}

(Received September 20, 2002, accepted November 20, 2002)

\begin{abstract}
Two patients with amyopathic dermatomyositis complicated by interstitial lung lesions were effectively treated with a combination of corticosteroids and cyclosporine and/or cyclophosphamide. A 48-year-old female patient was treated with pulse methylprednisolone and cyclosporine 2 months after onset of dermal symptoms. A 45-year-old male patient was treated with oral prednisolone and pulse cyclophosphamide 2 1/2 months after onset of dermal symptoms. Early evaluation of interstitial lung lesions and early extensive therapy may improve prognosis of interstitial lung lesions in patients with amyopathic dermatomyositis.
\end{abstract}

Key words : interstitial lung lesion, immunosuppressant, combination therapy

\section{INTRODUCTION}

Amyopathic dermatomyositis (ADM) is defined as dermatomyositis (DM) with a typical skin rash but without muscle involvement ${ }^{1)}$. Interstitial lung disease (ILD) occurs in both patients with DM and ADM. However, ILD progresses more rapidly in $\mathrm{ADM}$ patients than in $\mathrm{DM}$ patients, resulting in relatively poor prognosis for ADM complicated by $\operatorname{ILD}^{2-6)}$. To treat ILD in patients with $\mathrm{ADM}$, corticosteroids or combinations of corticosteroids and immunosuppressants have been used, but none of these therapies have produced promising results. There have been a few case reports in which ILD in ADM patients were effectively treated using cyclosporine ${ }^{7-9)}$, cyclophosphamide $^{10,11)}$ or methotrexate ${ }^{12)}$. The efficacy of therapy depends on

杉崎康太，武田功，岩館治代，菅野孝，西間木友衛，粕川禮司

Reprint requests to: Kota Sugisaki, Division of Rheumatology, Fukushima Rosai Hospital, Iwaki City, 973-8403, Japan. 
several factors: severity of the lung injury at the time therapy is started; type and dose of the drugs used; pathohistology of the involved lung (usual interstitial pneumonia [UIP], bronchiolitis obliternas organizing pneumonia [BOOP] or diffuse alveolar damage $[\mathrm{DAD}])$. We report 2 ADM patients with ILD who were effectively treated using combination therapy : corticosteroid and cyclosporine for one patient, and corticosteroid and cyclosporine/cyclophosphamide for the other patient. In both patients, the therapy was started in the early stage of lung disease.

\section{CASE REPORT}

\section{Case 1}

A 48-year-old female patient first experienced erythema with slight itching in the back, palm and periunguinal regions of both hands in early October, 2000. By the middle of October, 2000, the erythema had spread to the forehead, middle back and abdominal wall. The patient visited the Division of Dermatology, Iwaki Municipal Hospital. There, she was diagnosed with dermatitis and treated with steroid ointment. Around October 20th, 2000, the patient experienced polyarthralgia in the bilateral wrists, metacarpophalangeal (MCP) joints, proximal interphalangeal (PIP) joints, elbows and knees. The laboratory findings for blood samples obtained on October 21st, 2000, were as follows: lactate dehydrogenase (LDH), 818 IU/1 (normal, less than 420) ; creatine kinase (CK), 52 IU/1 (normal, less than 140); Creactive protein (CRP), $0.8 \mathrm{mg} / \mathrm{dl}$ (normal, less than 0.2 ) ; erythrocyte sedimentation rate $(\mathrm{ESR}), 46 \mathrm{~mm} / \mathrm{h}$; antinuclear antibody (ANA), $80 \times$ (normal, less than $40 \times$ ).

The patient was admitted to the Division of Rheumatology, Ohta Nishinouchi Hospital, on December 4th, 2000. On admission, erythema was observed on the bilateral extensor side of the MCP and PIP joints, bilateral ear tags, forehead, middle back and abdominal wall. Swelling of the bilateral PIP joints and wrists was observed. The patient did not complain of myalgia, muscle weakness or respiratory distress. Heart sounds were clear, and the patient had a normal pulse rate $(60 / \mathrm{min})$ and blood pressure $(132 / 78 \mathrm{mmHg})$. Weak Velcro rales were audible at the bilateral bases of the lung fields. There were no findings of Raynaud's phenomenon or scleroderma. Computed tomography (CT) of the chest revealed increased intensity of the interstitial lung figures in the bilateral lower back areas (Fig. 1[A]). Laboratory findings of the blood samples obtained on December 5th, 2000, were as follows: white blood cells (WBC), 6400/ $\mathrm{mm}^{3}$ (normal, 3500-9000) ; $\mathrm{CRP}, 0.39 \mathrm{mg} / \mathrm{dl}$ (normal, less than 0.2) ; aspartate aminotransferase (AST), $27 \mathrm{IU} / 1$ (normal, 9-35) ; alanine aminotransferase (ALT), 17 IU/1 (normal, 5-40) ; LDH, 420 IU/1 (normal, less than 220); CK, $51 \mathrm{IU} / 1$ (normal, 40-150); free T4, $0.88 \mathrm{ng} / \mathrm{ml}$ (normal, 0.71-1.85) ; TSH, $1.5 \mathrm{IU} / \mathrm{ml}$ (normal, 0.46-3.70); negative for rheumatoid factor (RF), rheumatoid arthritis particle agglutination (RAPA), anti-nuclear antibodies and antibodies to Jo-1, Scl-70 and ds-DNA ; serum CH50, $54.4 \mathrm{IU} / \mathrm{dl}$ (normal, 30-50) ; C3, $116 \mathrm{mg} / \mathrm{dl}$ (normal, 86-160) ; C4, $22.4 \mathrm{mg} / \mathrm{dl}$ (normal, 17-45) ; myoglobin, 


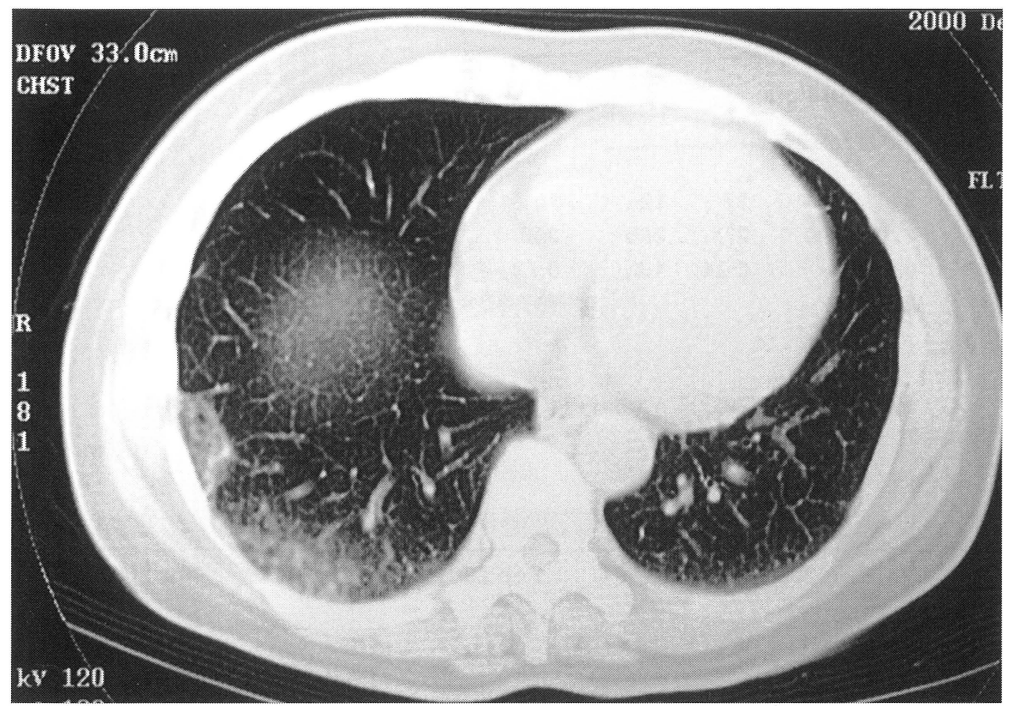

A

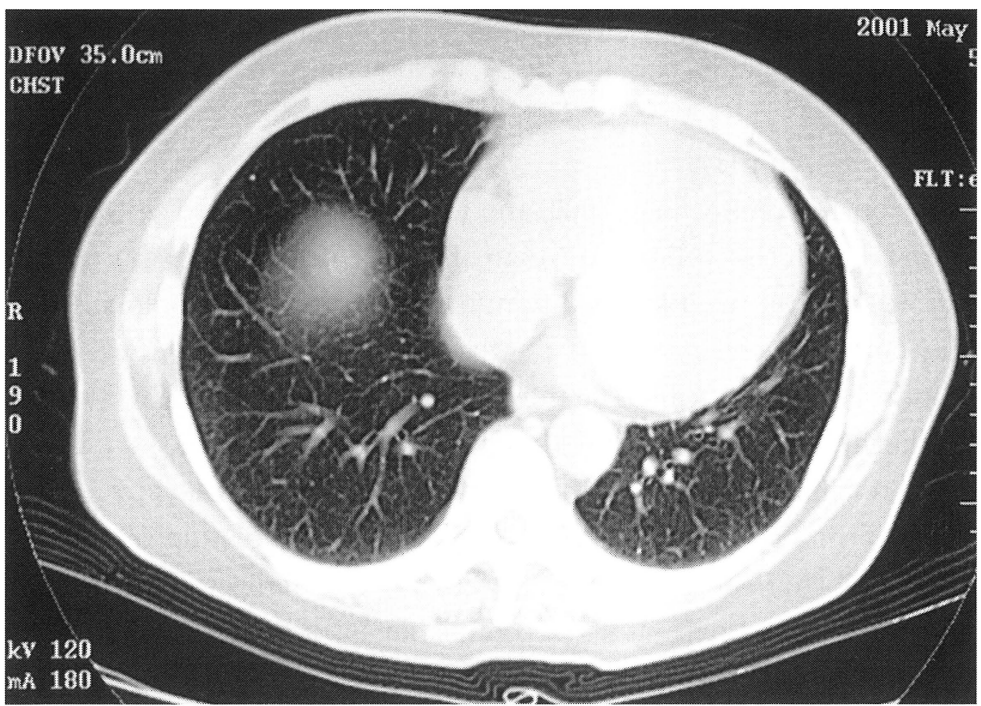

$\mathrm{B}$

Fig. 1 [A] and [B] : Computed tomography (CT) of the chest of patient 1. CT image taken on December 4th, 2000, [A] showed increased intensity of interstitial lung figures in the bilateral lower lung fields, especially in the right field. CT image taken on May 26th, 2001, [B] showed reduced intensity of the interstitial lung figures in the bilateral lower lung fields.

$22 \mathrm{ng} / \mathrm{ml}$ (normal, less than 61) ; aldolase, $4.6 \mathrm{IU} / 1$ (normal, less than 5.9) ; surfactant protein D (SP-D), $22.1 \mathrm{ng} / \mathrm{ml}$ (normal, less than 110). Urinalysis revealed no abnormalities. Results of gas analysis of the arterial blood were as follows: $\mathrm{PaO}_{2}, 94.3$ 


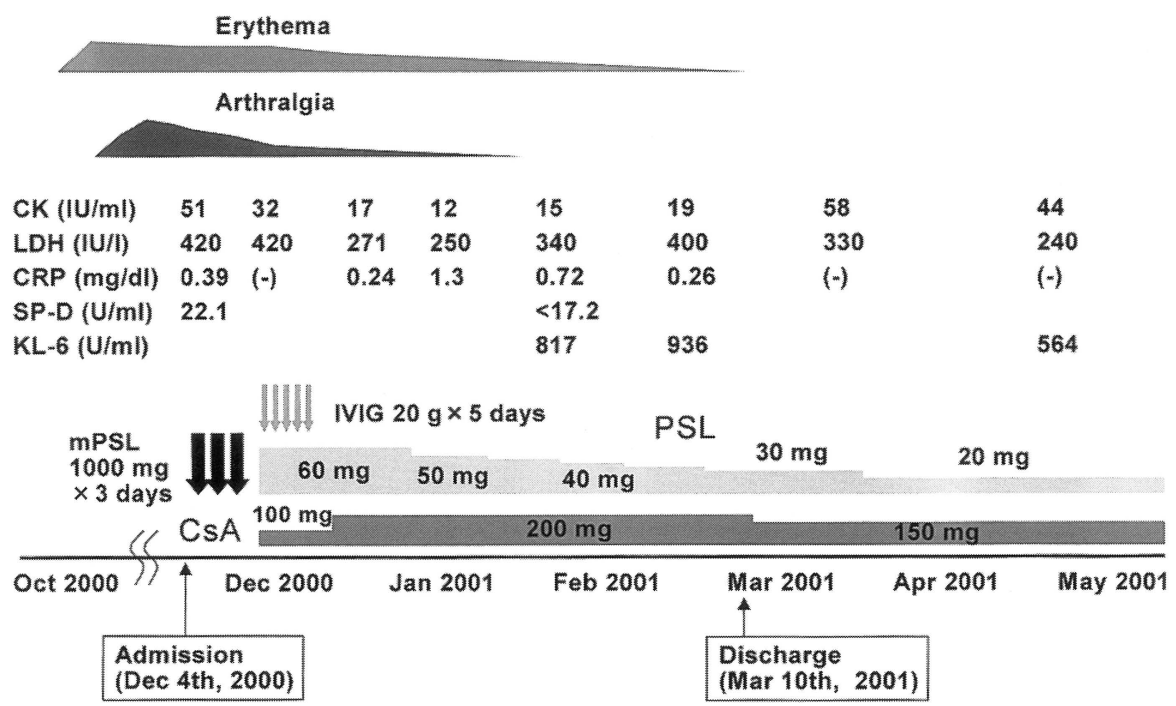

Fig. 2 Clinical course of patient 1. Severity of the erythema and arthralgia, laboratory data and the drugs and doses used in therapy.

$\mathrm{CK}$, creatine kinase; LDH, lactate dehydrogenase; CRP, C-reactive protein; SP-D, surfactant protein D; IVIG, intravenous immunoglobulin ; mPSL, methylprednisolone; PSL, prednisolone; CsA, cyclosporin A.

$\mathrm{mmHg} ; \mathrm{PaCO}_{2}, 34.5 \mathrm{mmHg}$.

Beginning on December 4th, 2000, the patient was treated with a combination therapy consisting of the following : drip infusion of $1000 \mathrm{mg} /$ day of methylprednisolone for 3 days, followed by oral administration of prednisolone (PSL) starting at $60 \mathrm{mg} /$ day and reduced gradually ; intravenous infusion of $10 \mathrm{~g} /$ day of human immunoglobulin for 5 days; and $200 \mathrm{mg}$ /day of cyclosporine. Two weeks after the start of the therapy, the severity of the skin lesions was reduced. LDH and CRP were at nearly normal levels 6 months after the start of the therapy. The chest CT taken on May 26th, 2001, five and a half months after the start of therapy, showed reduced, almost normal, intensity of interstitial lung figures, as seen in Fig. 1[B]. The clinical course of the patient's symptoms, her laboratory data and the drugs and doses used in her treatment are shown in Fig. 2.

\section{Case 2}

A 45-year-old male began to exhibit erythema of the nose and hands and complain of arthralgia of the wrists and PIP joints at the end of September, 2000. The arthralgia spread to the bilateral ankles, knees and shoulders. The patient observed a very slight reduction of muscle power in the lower extremities. The erythema spread, first to the foreneck and forechest, then to the extensor side of the MCP joints of the bilateral 2nd and 3rd fingers, and finally to the malleolus fibrae. The patient visited Nishimaki Clinic on November 5th, 2000.

The laboratory findings for the blood samples obtained on November 10th, 2000, 
at Nishimaki Clinic were as follows: WBC, 4,000/mm³ ; CK, $141 \mathrm{IU} / 1$ (normal, less than 140) ; LDH, 813 IU/1 (normal, less than 400); AST, $56 \mathrm{IU} / \mathrm{ml}$; ALT, 75 IU/ml ; negative for $\mathrm{CRP}$ and $\mathrm{RF}$. The patient was diagnosed with dermatomyositis, referred to the Division of Rheumatology, Ohta Nishinouchi Hospital, on November 25th, 2000, and admitted in the Division of Rheumatology on December 8th, 2000. The laboratory findings for the blood samples obtained on December 8th were as follows: WBC, 6200/mm³ ; CK, $110 \mathrm{IU} / 1$; LDH, $276 \mathrm{IU} / 1$; AST, $41 \mathrm{IU} / 1$; ALT, 67 $\mathrm{IU} / 1$; myoglobin, $51 \mathrm{ng} / \mathrm{ml}$; KL-6 (serum surfactant protein), $1360 \mathrm{U} / \mathrm{ml}$ (normal, less than 500). The patient did not complain of respiratory distress. However, CT of the chest taken on December 4th, 2000, showed slightly increased intensity of the interstitial lung figures in the lower and upper dorsal fields of the bilateral lungs (Fig. $3[\mathrm{~A}]$ ), which was only barely detected in the chest X-ray. Gas analysis of the arterial blood showed slightly decreased $\mathrm{PaO}_{2}: 81.0 \mathrm{mmHg}$. The patient was diagnosed with amyopathic dermatomyositis, and administration of PSL began on December 15th, starting at a dose of $60 \mathrm{mg}$ /day and gradually reduced. Administration of cyclosporine at a dose of $100 \mathrm{mg} /$ day began on December 25th. One week after the start of cyclosporine administration, ALT was found to be elevated (324 $\mathrm{IU} / \mathrm{l})$. At the point, the administration of cyclosporine was stopped and drip infusion of pulse cyclophosphamide, $1000 \mathrm{mg}$ per day for one month, was started. The chest CT taken on April 28th, 2001, five months after the start of the combination therapy, showed no progression of the intensity of the interstitial lung figures in the bilateral lower and upper dorsal fields (Fig.3[B]). Thereafter, laboratory data values remained at normal levels, with the exception of an elevated level of KL-6 (1260 U/ml). The clinical course of the patient's symptoms, his laboratory data and the drugs and doses used in his therapy are shown in Fig. 4.

\section{DISCUSSION}

The 2 patients presented in this report satisfy the definition of amyopathic dermatomyositis ${ }^{1}$, because both patients developed dermal symptoms typical of dermatomyositis without clinically significant evidence of muscle weakness such as disturbance of daily activities or elevation of serum creatine kinase. As is the case with patients with idiopathic interstitial lung disease, treatment of interstitial lung disease in patients with connective tissue diseases is difficult. Corticosteroids and immunosuppressants are used to treat ILD in patients with connective tissue disease, including $\mathrm{ADM}$ patients. Among the immunosuppressants that have been used, cyclosporine $^{7-9)}$, cyclophosphamide ${ }^{10,11)}$ and methotrexate ${ }^{12)}$ have been found to be effective in treating ILD. The efficacy of a drug for treatment of ILD appears to depend on various factors, including severity of the lung injury and pathohistology of the involved lung. Obviously, beginning treatment in the early stage of interstitial lung disease can improve prognosis. Reports in the literature indicate that prognosis of ILD in patients with ADM is better when the therapy is started within 


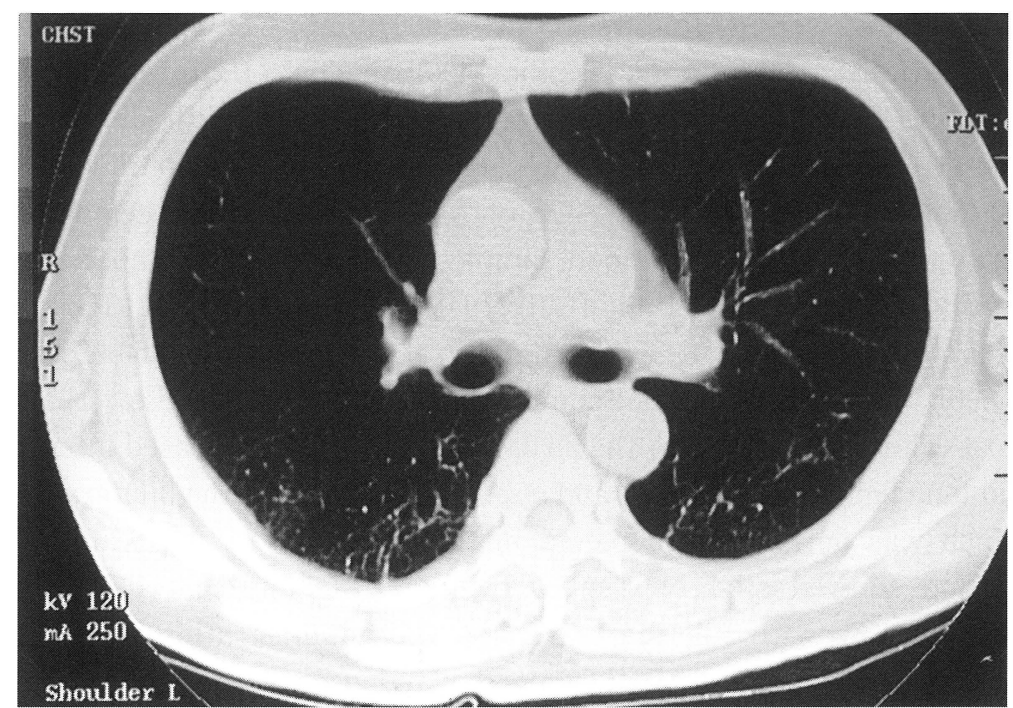

A

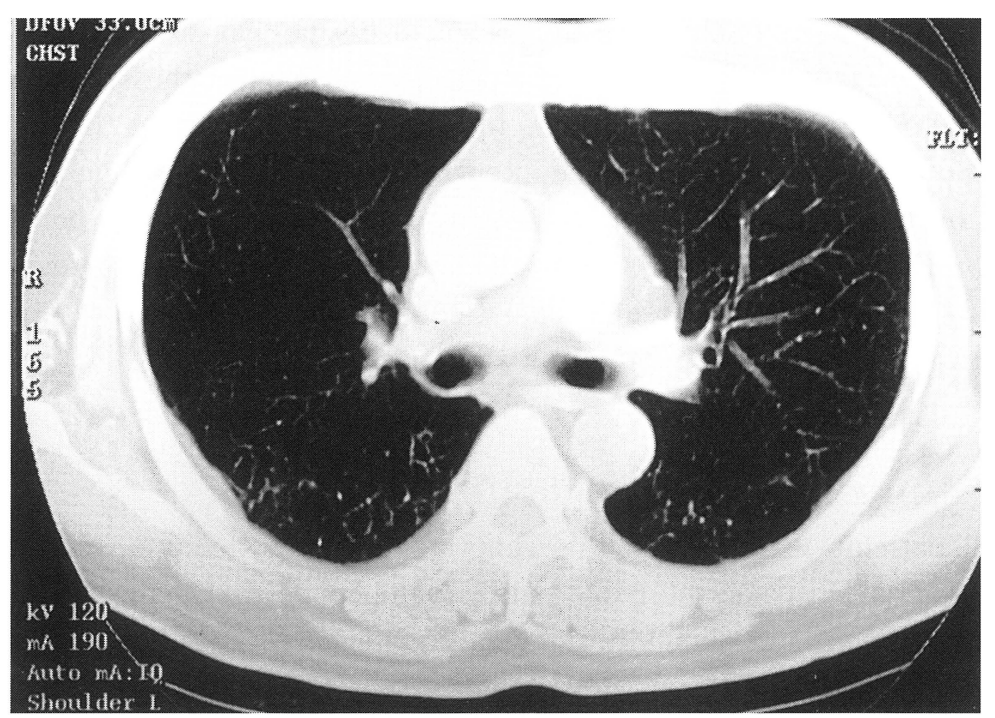

$\mathrm{B}$

Fig. 3 [A] and [B]: Computed tomography (CT) of the chest of patient 2. CT image taken on December 4th, 2000, [A] showed slightly increased intensity of the interstitial lung figures in the bilateral lower lung fields [A]. CT image taken on April 28th, 2001, [B] showed unchanged intensity of the interstitial lung figures in the bilateral lower lung fields.

2 months after onset of interstitial lung disease, although it is difficult to determine the exact time at which a lung lesion formed. Ozawa et al. ${ }^{9}$ reported improvement of ILD in a patient with ADM whose combination therapy consisting of corticoster- 


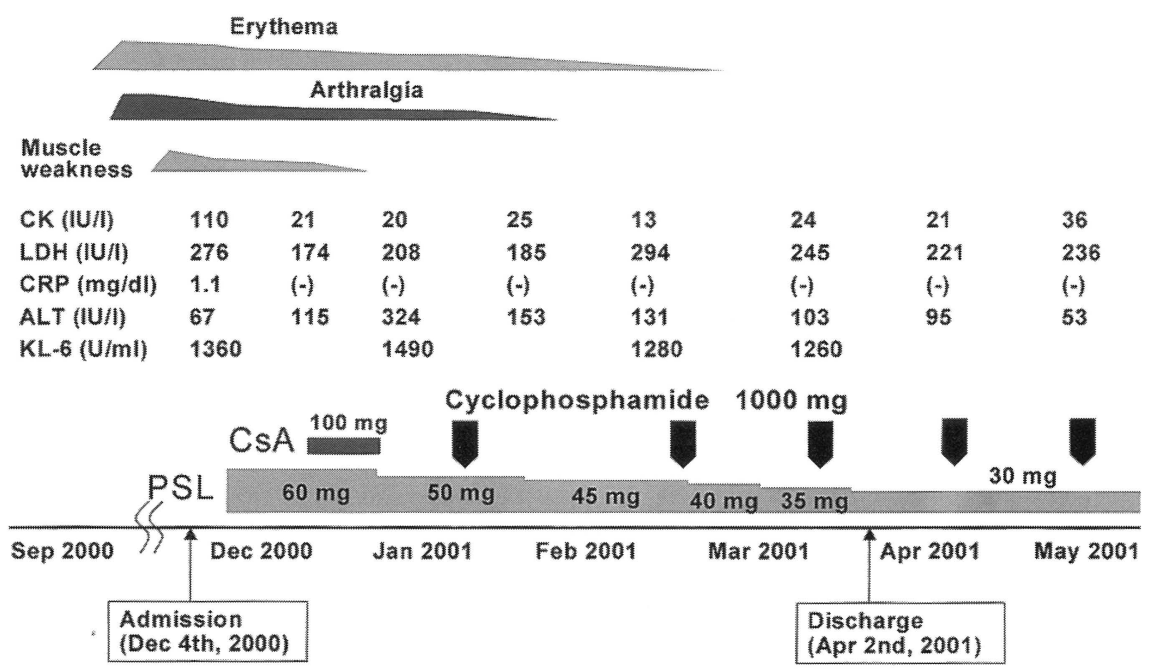

Fig. 4 Clinical course of the patient 2. Severity of erythema, arthralgia and muscle weakness, laboratory data and the drugs and doses used in therapy.

$\mathrm{CK}$, creatine kinase; LDH, lactate dehydrogenase; CRP, C-reactive protein; ALT, alanine aminotransferase; CsA, cyclosporin A; PSL, prednisolone.

oids and cyclosporine started one month after the onset of lung disease, although the patient's $\mathrm{PaO}_{2}$ remained low $(56 \mathrm{mmHg})$. Arterial oxygen pressure of the patients at the time that therapy is started can also predict prognosis of ILD. In a report by Ozawa et al. ${ }^{9}$, in which only one of 4 ADM patients with ILD survived, the surviving patient had a $\mathrm{PaO}_{2}$ of $83.1 \mathrm{mmHg}$, and the 3 deceased patients had $\mathrm{PaO}_{2}$ values below $80 \mathrm{mmHg}$. The two patients in the present report were treated within 2 months after onset of the disease and, therefore, presumably within 2 months after onset of ILD. Arterial oxygen pressure of the 2 survived patients in the present report was above $80 \mathrm{mmHg}$ (case 1, $98 \mathrm{mmHg}$; case 2, $81.3 \mathrm{mmHg}$ ), which accorded with their report. As for pathohistology of the lung, it has been reported that BOOP lung lesions are associated with better prognosis than DAD lung lesions in ILD patients. In a report by Toyoshima et al. ${ }^{7)}$, in which only one of 4 ADM patients with ILD survived, the surviving patient had a lung lesion consisting of regional alveolar damage, whereas the 3 deceased patients had DAD lung lesions, although all 4 patients were started on combination therapy with PSL and pulse cyclophosphamide 8 months after onset of dyspnea. A surviving ADM patient with ILD reported by Takashi et al. ${ }^{11)}$ had a BOOP lung lesion, as indicated by an open-biopsied pulmonary specimen. The lungs of the 2 patients in the present report were not examined histologically. However, chest CT images showed the beginnings of interstitial lung lesions restricted to the back and lateral regions of the lung fields, thus resembling lesions typical of interstitial pneumonia. It is sometimes very difficult to perform early evaluation of interstitial lung disease in connective tissue disease patients using ordinary laboratory tests and chest X-ray examination. Chest CT is essential for 
evaluation of early lesions of interstitial lung disease. In addition, assays for protein products of alveolar type II epithelial cells, such as surfactant protein-A (SP-A), SP-D and KL-6, can aid detection of the early-stage interstitial lung lesions, as shown in case 2 of the present report.

We thus conclude that, early detection of ILD and extensive therapy with a combination of corticosteroids and immunosuppressants may prevent progression of interstitial lung lesions to life-threatening stages in patients with ADM.

\section{REFERENCES}

1. Euwer RL, Sontheimer RD, Amyopathic dermatomyositis (dermatomyositis sine myositis): presentation of six new cases and review of the literature. J Am Acad Dermatol, 24, 959-66, 1991.

2. Takizawa H, Shiga J, Moroi Y, Miyachi S, Nishimaki M, Miyamoto T, Interstitial lung disease in dermatomyositis: clinicopathological study. J Rheumatol, 14, 102-7, 1987.

3. Fernandes L, Goodwill CJ, Dermatomyositis without apparent myositis complicated by fibrosing alveolitis. J Roy Soc Med, 72, 777-9, 1979.

4. Tokiyama K, Tagawa H, Yokota E, et al., Two cases of amyopathic dermatomyositis with fatal progressive interstitial pneumonitis. Ryumachi, 30, 204-11, 1990. (in Japanese)

5. Santiago MB, Chalhoud M, Tadeu-Pereira S, Amyopathic dermatomyositis complicated by interstitial pulmonary disease and pneumomediastinum. J Rheumatol, 25, 2042-3, 1998.

6. Chow SK, Yeap SS, Amyopathic dermatomyositis and pulmonary fibrosis. Clin Rheum, 19, 484-5, 2000.

7. Toyoshima M, Sato A, Chiba K, et al., Clinicopathological features of interstitial pneumonia associated with amyopathic dermatomyositis. Nihon Kyobu Shikkan Gakkai Zasshi, 35, 281-7, 1997. (in Japanese)

8. Nawata Y, Kurasawa K, Takabayashi K, et al., Corticosteroid resistant interstitial pneumonitis in dermatomyositis/polymyositis: Prediction and treatment with cyclosporine. J Rheumatol, 26, 1527-33, 1999.

9. Ozawa Y, Kurosaka D, Yokoyama T, Tajima N, Therapeutic efficacy of cyclosporin A in four cases of amyopathic dermatomyositis with rapidly progressive interstitial pneumonia. Ryumachi, 40, 798-809, 2000. (in Japanese)

10. Tahara K, Nishiya K, Hisakawa N, Hashimoto K, Hara I, Kodama H, A case of amyopathic dermatomyositis associated with interstitial pneumonitis. Ryumachi, 37, 714-8, 1997. (in Japanese)

11. Takashi S, Okubo Y, Yamazaki Y, Koizumi T, Sekiguchi M, Amyopathic dermatomyositis with interstitial pneumonia: Effective treatment with cyclophosphamide pulse therapy. Nihon Kokyuki Gakkai Zasshi, 37, 647-51, 1999. (in Japanese)

12. Itoh T, Mitsuoka S, Uji M, Matsushita H, Successful combination chemotherapy with low-dose methotrexate and steroids for dermatomyositis complicated by interstitial pneumonitis. Nihon Kokyuki Gakkai Zasshi, 37, 636-40, 1999. (in Japanese) 